The following books have been received and will be deposited in the BASM Library c/o NSMI:

Shipe Jr. JR, Savory J. Drugs in Competitive Athletes: Proceedings of the First International Symposium held on the Islands of Brioni, Yugoslavia 29 May - 2 June 1988. Oxford, UK: Blackwell Scientific Publications, 1991.

French S, ed. Physiotherapy: a Psychological Approach. Oxford, UK: Butterworth-Heinemann, 1992.

\section{Sports Injuries: Recognition and Management}

M. A. Hutson

Oxford, UK: Oxford University Press, ISBN 019261 7508, 1990, 234 pages. Illustrated. $£ 45.00$

This book is a multiple-author text with the major contribution coming from the editor. The specialist sections are coauthored with acknowledged experts in their specialist fields and where necessary the editor has added examples of examination technique. In some of the chapters, such as injuries to the shoulder, this has worked well. The clinical examination of the knee photographs do not add to the clarity of clinical examination. In the chapter on radiological investigations I am surprised to see an arthrogram of the knee as most centres would use magnetic resonance imaging for assessment of intra-articular pathology. The section on treatment and rehabilitation shows many injection techniques. For the lumbar spine it suggests that it is possible to inject facet joints without radiographic control. This is at the least controversial.

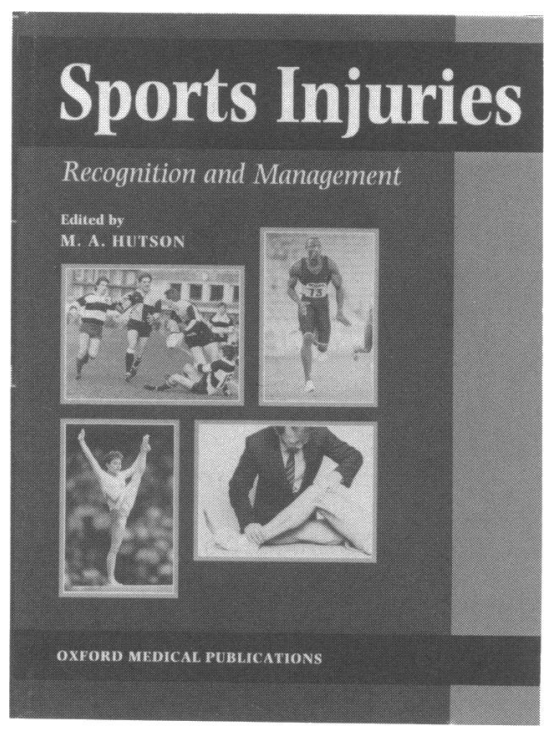

The text will be useful for the general practitioner to obtain an overall picture of the diversity of sports injuries. I would recommend this book for this purpose.

\section{J. F. Dooley FRCS FRCSC}

\section{Guidelines for Exercise Testing and Prescription - 4th Edition}

American College of Sports Medicine Philadelphia, Pennsylvania, USA: Lea and Febiger, 1991, 314pp

Every five years or so a new edition of the ACSM 'Guidelines' is published, an event which many exercise physiologists look forward to, and the current issue lives fully up to expectations. It is divided into 12 chapters, with a preface which somewhat disarmingly notes that 'exercise ... is more beneficial to health than previously thought'. Suitably, Chapter 1 is concerned with risks and safety, with statistics such as 'Death during vigorous exercise is rare, perhaps occurring at a rate of one death per year per 15000-20000 adult exercisers. The risk of primary cardiac arrest is slightly higher (21 compared to 18 events per $10^{8}$ person-hours) during exercise in regular exercisers than the overall risk for sedentary men, although the overall risk for active men is much lower than sedentary men (five compared to 18 deaths per $10^{8}$ person-hours). Also, the commonsense statement is made that 'Most persons, except for those with known serious disease', can begin a gently progressive exercise programme of $40-60 \%$ maximum oxygen uptake,' without a medical evaluation or exercise test'.

Chapter 2 is an excellent 20-page précis of clinical exercise physiology, followed by an equal section on physical fitness testing which, oddly enough, makes no mention of any of the forms of the 'Wingate Test' under a heading of 'Muscular Endurance' whose discussion ranges from sit-ups and pull-ups to the use of isokinetic dynamometers.

As might be expected in a primarily medical book there is a comparatively large chapter on guidelines for administering exercise tests, followed by a quarter of the whole book on principles of exercise prescription in three chapters, first for general health related fitness, then for cardiac patients and finally those with special exercise needs such as diabetes, asthma, emphysema, renal disease and transplantation, among others. The book concludes with information on administering and personnel aspects of exercise programmes. A lot of good information is included in a small space, in a paperback not much larger than a Penguin book.

\section{N. C. Craig Sharp PhD MRCVS}

\section{Hand Injuries in Athletes}

J. W. Strickland and A. C. Rettig London: W. B. Saunders, Harcourt Brace Jovanovich, 1992: 284 pp, £39.50, ISBN $072162779 \mathrm{X}$

The digits of the hand are named thumb (pollex), index (indicis), middle (medius or obscenus), ring (annularis), little (minimus or auricularis). The Secretary of The Medical Defence Union wrote in 1955 'To do as many do, namely to number the fingers 1,2 , 3 etc. and to record in the clinical notes for example that finger 3 requires amputation is to set the stage for a surgical calamity'. It was, therefore, extraordinary to find in a book of this calibre in the caption to Figure 4.12 that the middle finger was referred to as the player's 'fourth' finger. I can only hope that if he came to surgery the affected digit was marked in some way as indeed is our routine practice.

There are some errors of omission, such as the common and important injuries to the nail and nail bed, the essentials of early management of degloving injuries and serious skin lacerations often seen in sport and the sometimes very troublesome subluxations of the pisiform in racket players. The book cannot otherwise be faulted. One of the highlights is the opening chapter by James Strickland, one of the editors, who is a doyen of American hand surgery. His philosophy for management of sporting injuries is mandatory reading for all who have to treat athletes.

I found the chapter on epidemiology especially interesting. They estimate hand injury to comprise almost $10 \%$ of all sporting injuries. Our own records show the figure to be nearer $20 \%$ with sports such as boxing showing the proportion to be a third of all injuries in that sport.

This book is a welcome addition to the library of all who care for sports people.

\section{Basil Helal MCh(Orth), FRCS}

